\title{
Article \\ A Multi-Criteria Assessment Strategy for 3D Printed Porous Polyetheretherketone (PEEK) Patient-Specific Implants for Orbital Wall Reconstruction
}

\author{
Neha Sharma ${ }^{1,2}$, Dennis Welker ${ }^{2}$, Soheila Aghlmandi ${ }^{3}$, Michaela Maintz ${ }^{2,4}$, Hans-Florian Zeilhofer ${ }^{1}$, \\ Philipp Honigmann ${ }^{2,5,6} \mathbb{D}$, Thomas Seifert ${ }^{7}$ and Florian M. Thieringer $1,2, * \mathbb{D}$
}

1 Clinic of Oral and Cranio-Maxillofacial Surgery, University Hospital Basel, CH-4031 Basel, Switzerland; neha.sharma@usb.ch (N.S.); hans-florian.zeilhofer@usb.ch (H.-F.Z.)

2 Medical Additive Manufacturing Research Group (Swiss MAM), Department of Biomedical Engineering, University of Basel, CH-4123 Allschwil, Switzerland; dennis.welker@gmail.com (D.W.); michaela.maintz@unibas.ch (M.M.); philipp.honigmann@ksbl.ch (P.H.)

3 Basel Institute for Clinical Epidemiology and Biostatistics, Department of Clinical Research, University Hospital Basel, CH-4031 Basel, Switzerland; soheila.aghlmandi@usb.ch

4 Institute for Medical Engineering and Medical Informatics, University of Applied Sciences and Arts Northwestern Switzerland, CH-4132 Muttenz, Switzerland

5 Hand Surgery, Cantonal Hospital Baselland, $\mathrm{CH}-4410$ Liestal, Switzerland

6 Department of Biomedical Engineering and Physics, Amsterdam UMC, University of Amsterdam, Amsterdam Movement Sciences, NL-1105 Amsterdam, The Netherlands

Citation: Sharma, N.; Welker, D.; Aghlmandi, S.; Maintz, M.; Zeilhofer, H.-F.; Honigmann, P.; Seifert, T.; Thieringer, F.M. A Multi-Criteria Assessment Strategy for 3D Printed Porous Polyetheretherketone (PEEK) Patient-Specific Implants for Orbital Wall Reconstruction. J. Clin. Med. 2021, 10, 3563. https://doi.org/ $10.3390 / \mathrm{jcm} 10163563$

Academic Editors: Samer Srouji and Gianrico Spagnuolo

Received: 4 July 2021

Accepted: 10 August 2021

Published: 13 August 2021

Publisher's Note: MDPI stays neutral with regard to jurisdictional claims in published maps and institutional affiliations.

Copyright: (c) 2021 by the authors. Licensee MDPI, Basel, Switzerland. This article is an open access article distributed under the terms and conditions of the Creative Commons Attribution (CC BY) license (https:// creativecommons.org/licenses/by/ $4.0 /)$.
7 Department of Mechanical and Process Engineering, University of Applied Sciences, DE-77652 Offenburg, Germany; thomas.seifert@hs-offenburg.de

* Correspondence: florian.thieringer@usb.ch

\begin{abstract}
Pure orbital blowout fractures occur within the confines of the internal orbital wall. Restoration of orbital form and volume is paramount to prevent functional and esthetic impairment. The anatomical peculiarity of the orbit has encouraged surgeons to develop implants with customized features to restore its architecture. This has resulted in worldwide clinical demand for patient-specific implants (PSIs) designed to fit precisely in the patient's unique anatomy. Material extrusion or Fused filament fabrication (FFF) three-dimensional (3D) printing technology has enabled the fabrication of implant-grade polymers such as Polyetheretherketone (PEEK), paving the way for a more sophisticated generation of biomaterials. This study evaluates the FFF 3D printed PEEK orbital mesh customized implants with a metric considering the relevant design, biomechanical, and morphological parameters. The performance of the implants is studied as a function of varying thicknesses and porous design constructs through a finite element (FE) based computational model and a decision matrix based statistical approach. The maximum stress values achieved in our results predict the high durability of the implants, and the maximum deformation values were under one-tenth of a millimeter $(\mathrm{mm})$ domain in all the implant profile configurations. The circular patterned implant $(0.9 \mathrm{~mm})$ had the best performance score. The study demonstrates that compounding multi-design computational analysis with $3 \mathrm{D}$ printing can be beneficial for the optimal restoration of the orbital floor.
\end{abstract}

Keywords: blow-out; biocompatible materials; computer-aided design; finite element analysis; orbit; implant; orbital fracture; patient-specific modeling; printing; three-dimensional

\section{Introduction}

Pure orbital blowout fractures, also known as internal orbital floor fractures, occur within the confines of the internal orbital wall and do not affect the orbital rim or other facial bones. These fractures are common in individuals who experience blunt trauma to the facial and skull region [1-3]. The treatment of orbital blowout fractures is challenging mainly due to the restricted intraoperative view of the intricate and delicate anatomical 
region. Restoration of orbital form and volume is paramount to prevent functional and esthetic impairment $[4,5]$.

Currently, the conventional methods of orbital floor fracture reconstruction include the use of permanent, alloplastic non-resorbable biomaterials such as titanium meshes (prebend or prefabricated), plates, or polymeric implants (polyethylene, with embedded titanium mesh) $[6,7]$. Porous polyethylene implants are malleable and allow vascular ingrowth due to open pore structure. However, if placed close to extraocular muscles, it may form adhesions [8,9]. When utilizing conventional titanium meshes, pre- or intraoperative bending and shape adjustment are required, making the correct placement and location of the implants within the orbit a challenge. A typical issue associated with improperly positioned pre-bent plates is a lack of distal or medial support caused by damage to the orbital ledge and/or intra-orbital buttress [10-12]. The placement of orbital implants and their size and shape conformance to the unique anatomy of the injured components are critical factors in the overall success rate of orbital reconstruction, which has prompted surgeons to develop novel treatment options for orbital floor reconstructions [13,14].

With advances in computer-assisted surgery (CAS), orbital reconstructions have witnessed tremendous progress, dramatically improving both the functional and esthetic outcome of reconstructions with customized implants $[15,16]$. The customized or patientspecific implants (PSIs) enable patient-centric surgical plans and achieve precise orbital reconstructions [17-20]. Along with meticulous virtual surgical planning (VSP) and clinical examination, another pivotal component in treating orbital floor fractures is selecting the reconstructive material [21-23].

Over the last years, Polyetheretherketone (PEEK), a high-performance polymer, has gained significant popularity in reconstructive surgeries [24-27]. PEEK possesses a bonelike modulus of elasticity, excellent biocompatibility, high yield strength, and fatigue resistance, making it an appealing biomaterial for personalized implants in craniomaxillofacial surgery [28-30]. The adoption of PEEK for PSIs production was influenced by its favorable properties, including radiolucent characteristics with no artifact in medical imaging, stiffness, lightweight, and conventional computer-aided design/computer-aided manufacturing (CAD/CAM) procedures, specifically milling $[25,30]$. Few studies have reported using custom-made, non-porous, milled PEEK implants in orbital reconstructions $[19,31,32]$. However, these non-porous characteristics displaying hydrophobicity and bio-inertness of PEEK can limit its bioactivity and cause clinical concern in orbital floor reconstructions $[33,34]$.

Numerous attempts have been carried out to enhance the osseointegration potential of PEEK with surface coatings. Nonetheless, degradation and inadequate binding of the coatings to the PEEK implant surface resulting in osteolysis have been reported [35-37]. Another strategy is the introduction of porous structures, which has demonstrated promising results in increasing the osteogenic potential of PEEK [38-40]. The methods of fabricating three-dimensional (3D) porous structures are limited in conventional manufacturing technologies, and therefore, the clinical interest in additive manufacturing (AM) or 3D printing has rapidly grown $[35,38,41,42]$.

The anatomical peculiarity of the orbital region has encouraged surgeons to develop implants with customized characteristics to restore orbit architecture. This has resulted in worldwide clinical demand for PSIs designed to fit precisely in the patient's unique anatomy. With improvement in AM systems, the potential for customized 3D printed PEEK customized implants has surfaced, boosting interest in point-of-care (POC) manufacturing. Material extrusion-based or fused filament fabrication (FFF) 3D printing technology has previously been confined to low-temperature thermoplastics; however, the latest advances have enabled printing of high-temperature, implantable-grade thermoplastic polymers such as PEEK, paving the way for a more sophisticated generation of biomaterials. Implementing FFF at the POC offers numerous advantages such as less material wastage, easy operator training, faster implant production, increased cost-effectiveness, and patient specificity $[25,26,29,43]$. 
In orbital floor reconstruction, the implant's perfusion, permeability, and adequate mechanical strength are critical for long-term clinical success [21,44]. The characteristics of a porous implant are crucially dependent on its structure, which can significantly impact the mechanical response, defining its clinical applicability. Additionally, the design freedom capabilities of computer-aided design modeling and 3D printing significantly increase the possible combinations for an implant, resulting in various treatment choices for a specific case [42]. The design of porous constructs and implant thicknesses can thus affect the performance of orbital mesh implants. An essential factor to consider in such scenarios is the load-bearing capability of an implant under physiological conditions. From the biomechanical point of view, analyzing the implant's stress and deformation patterns can help understand better how the PEEK orbital mesh implants might respond to the orbital floor reconstruction regime. In this regard, computational models and simulations provide an estimate of the load-bearing capacity of the design before the fabrication of an implant $[45,46]$. Lastly, defects arising from the printing process and inadequate post-processing processes can significantly impact an implant's structural integrity and robustness. The printing feasibility and morphological characteristics of the respective implant dictate its conclusive clinical appropriateness and applicability.

There are currently no studies that provide an insight into the POC FFF 3D printing of PEEK orbital mesh customized implants. Therefore, this study aims to evaluate the performance of the FFF 3D printed PEEK orbital mesh implants with a metric considering the relevant design, biomechanical, and morphological parameters. To provide deeper insights, the complete in-house digital workflow from the pre-operative VSP to mechanical characteristics and FFF production of PEEK orbital mesh customized implants is studied as a function of varying thicknesses and porous design constructs through a finite element (FE) based computational model and a decision matrix based statistical approach.

\section{Materials and Methods}

The study workflow consisted of the following five protocols: (1) medical image processing and modeling of patient-specific orbital implants, (2) construction of PEEK orbital mesh implant design variants, (3) construction of computational models, (4) AM processes for PEEK orbital mesh implants, and (5) multi-criteria decision-making (MCDM) configuration assessment. Figure 1 illustrates a graphical flowchart summarizing the study workflow.

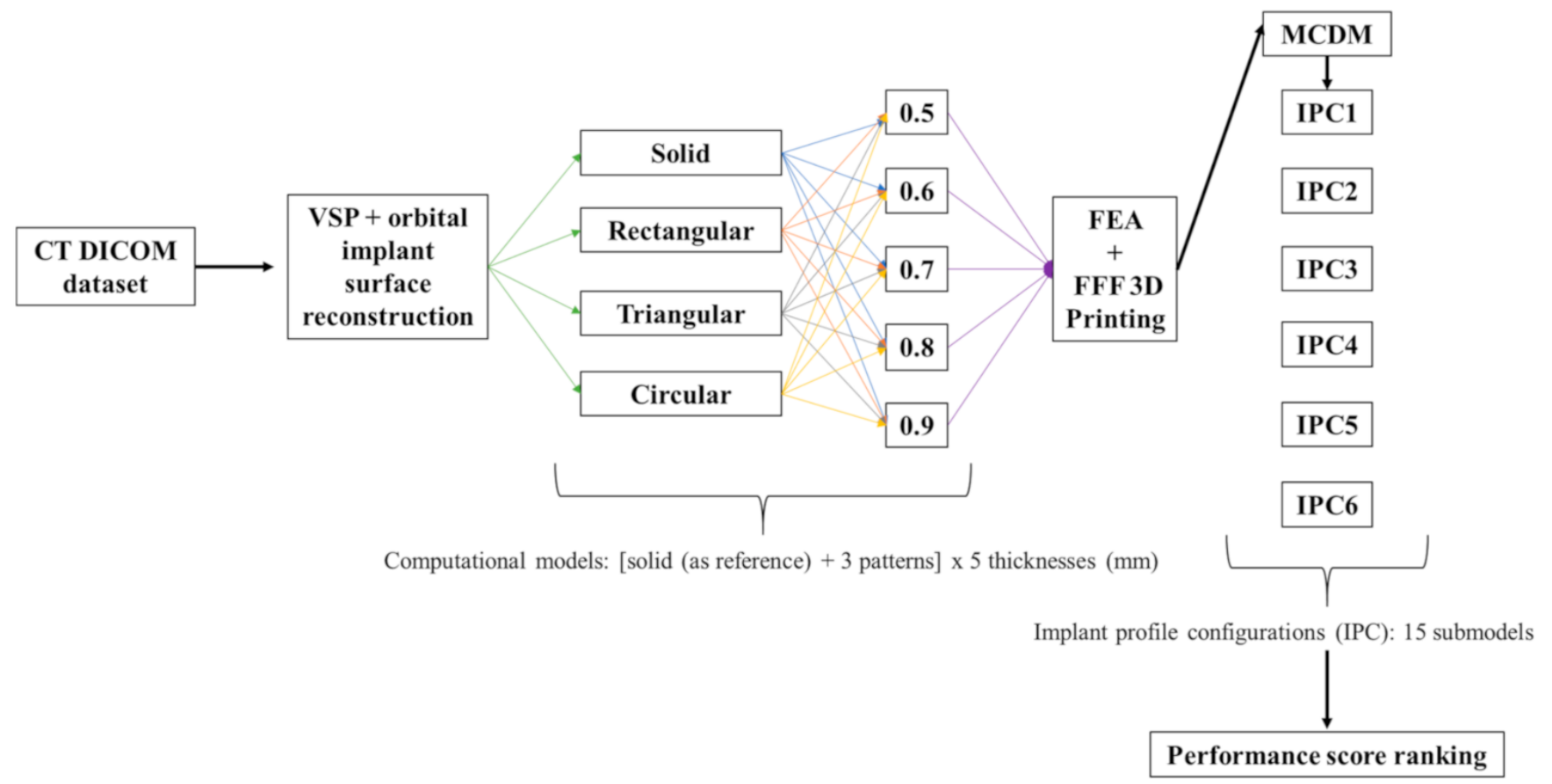

Figure 1. Graphical flowchart summarizing the study workflow. 


\subsection{Medical Image Processing and Modeling of Patient-Specific Orbital Implants}

An anonymized Digital Imaging and Communications in Medicine (DICOM) dataset of a unilateral orbital floor trauma was selected from the hospital's database for this workflow. A standard high-resolution computed tomography (CT) (Siemens SOMATOM, Siemens Healthcare $\mathrm{GmbH}$, Erlangen, Germany) for trauma protocol with the following parameters was used (matrix of $512 \times 512$ pixels, reconstruction slice thickness $0.75 \mathrm{~mm}$, seed per rotation of $1 \mathrm{~mm}$, gantry tilt $0^{\circ}$, bone window setting). The CT dataset was imported into a medical image processing software (Mimics Innovation Suite v. 22.0, Materialise, Leuven, Belgium). A 3D volumetric reconstruction of the skull model was generated using greyscale threshold-based segmentation, and the orbital region of interest (ROI) was selected (Figure 2).
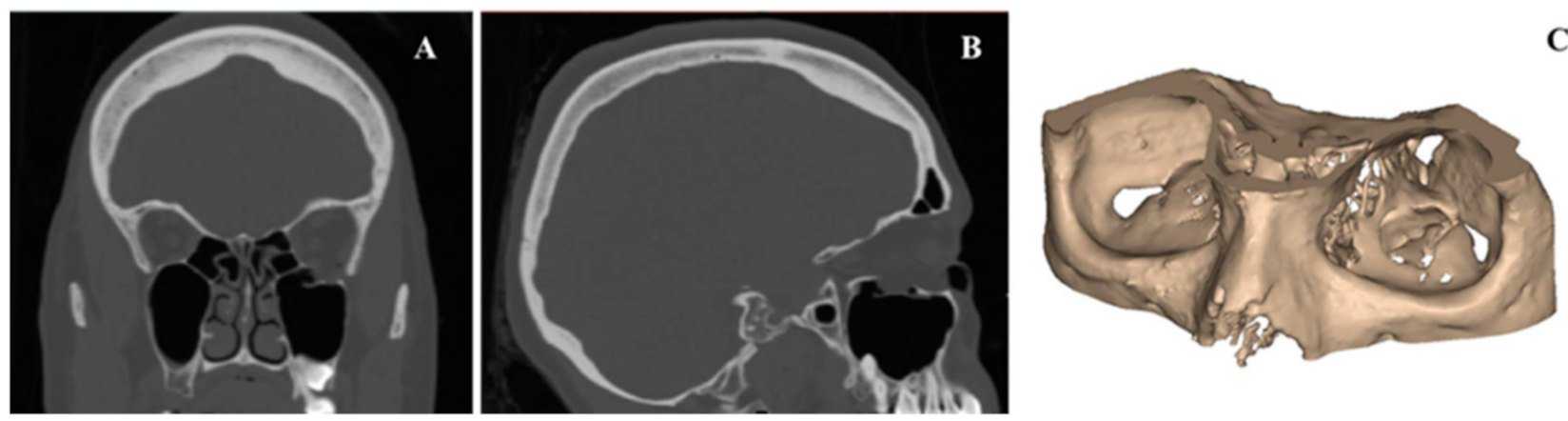

Figure 2. Medical image processing for the generation of a three-dimensional (3D) volumetric reconstruction of an exemplary case with left-sided orbital floor fracture. (A) Coronal view. (B) Sagittal view. (C) 3D volumetric reconstruction of the orbital region of interest.

The 3D virtual orbital model was then imported into certified CAD software for design modeling (3-matic Medical v. 14.0, Materialise, Leuven, Belgium). The unaffected (non-fractured) orbit was mirrored onto the contralateral side, i.e., the defect/fractured side. Due to fragile bony structures in orbit, all the air spaces were digitally reconstructed using fill hole freeform functionality and a spline-based algorithm (Figure 3A). This resulted in a virtual model of the orbit with smooth contour continuity. The digital reconstruction of the orbital floor was subsequently used as a reference to design the customized orbital implant (Figure 3B). A curve was delineated manually with an extend slightly larger than the orbital bone defect to have stable implant support. This reconstruction resulted in a covering of the defect with zero thickness, hereby referred to as a surface model of the orbital PSI (Figure 3C). This CAD file was saved and exported in the standard tessellation language (STL) file format.
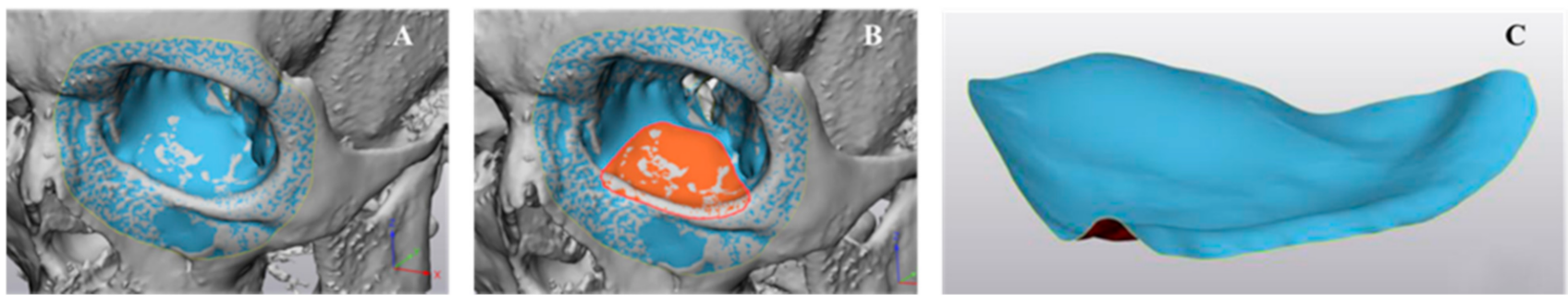

Figure 3. Virtual surgical planning (VSP) for the reconstruction of the orbital implant. (A) Mirroring the unaffected (blue) orbit to the contralateral side, i.e., the fractured side (grey), results in a fractured orbital floor's surface reconstruction. (B) Digital reconstruction of the orbital implant with smooth contour continuity. (C) Surface model of the customized orbital implant. 


\subsection{Construction of PEEK Orbital Mesh Implant Design Variants}

This step's main objective was to model thin orbital mesh implants in variable thicknesses and design variants. The surface model of the orbital PSI was imported in another CAD software (Autodesk Inventor v. 2020 for Windows, Autodesk Inc., San Rafael, CA, USA) for the subsequent modeling process. Using "sketch-driven pattern" functionality, three variable design patterns were selected. A solid (no design pattern) model was chosen as a reference, and three different porous constructs, herein referred to as "rectilinear", "triangular", and "circular", were modeled onto the orbital implant (Figure 4). Subsequently, using "mesh enabler" and "convert to freeform" functionalities, the surface model was extruded with appropriate thicknesses. In total, five thickness configurations were chosen for the orbital PSI, and implants with a thickness value of $0.5 \mathrm{~mm}, 0.6 \mathrm{~mm}, 0.7 \mathrm{~mm}, 0.8 \mathrm{~mm}$, and $0.9 \mathrm{~mm}$ were modeled. This resulted in a total of 15 orbital PSIs with desired model configuration profiles. For the sake of brevity, these configurations were systematically labeled using a two-character code. The first character in the code (an alphabet) denotes the specific design pattern, and the second character (a number) denotes the thickness of the implant. For instance, a label R07 denotes an implant with a rectangular design pattern and a thickness of $0.7 \mathrm{~mm}$.

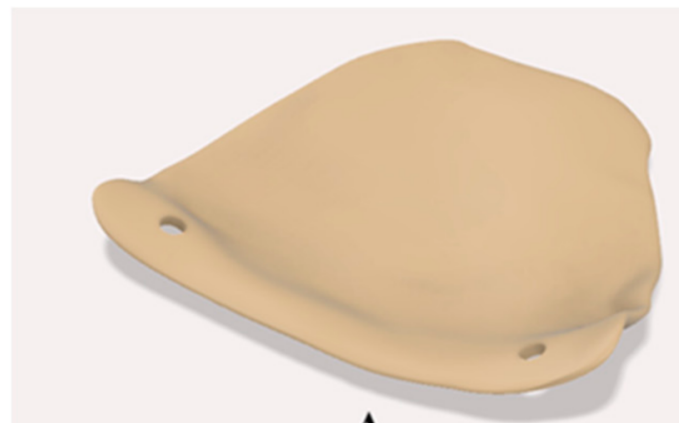

A

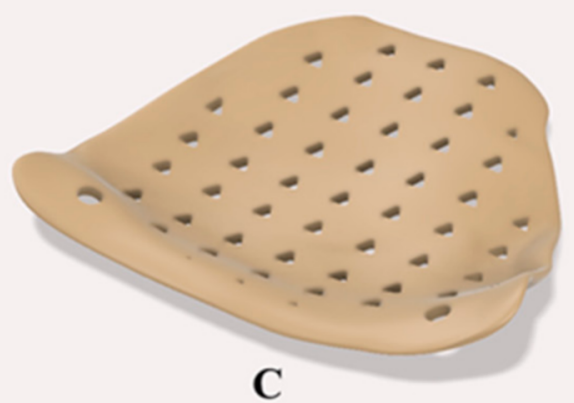

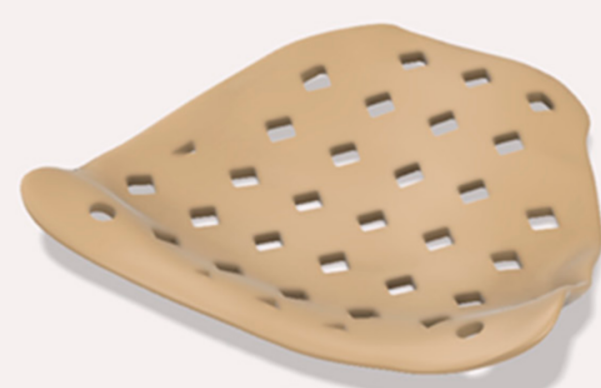

B

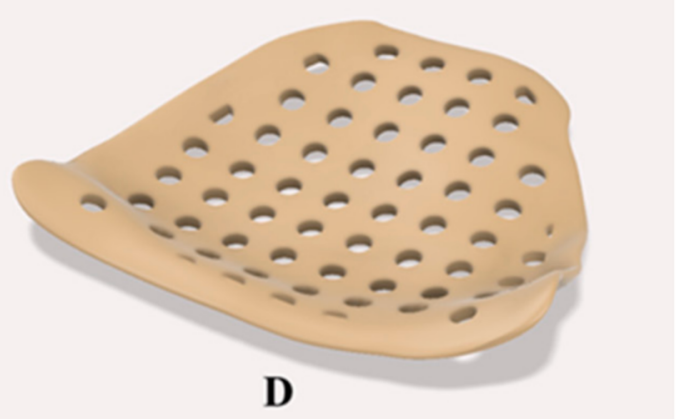

Figure 4. Construction of PEEK orbital mesh implant design variants. (A) Solid with no design pattern (reference). (B) Rectilinear pattern. (C) Triangular pattern. (D) Circular pattern.

\subsection{Construction of Computational Models}

To investigate the structural properties of the configured profiles, finite element (FE) models of the orbital mesh implants were created. The created geometric models of the individual profiles were simplified as shell models and constructed in Inventor Nastran software (Autodesk Inventor Nastran v. 2020 for Windows, Autodesk Inc., San Rafael, CA, USA). The simulation setup was designed to mimic a worst-case scenario in a pure orbital blowout fracture, confined within the internal orbital wall with no supporting bone structure underneath and no fracture involvement of the orbital rims. To design the simulation with clinically relevant forces, a vertical force of $0.3 \mathrm{~N}$ was considered, corresponding to the weight of an average eye of $30 \mathrm{~g}$. The loading force was distributed uniformly in a $4 \mathrm{~mm}$ diameter circular zone, located in the middle of the implant $10 \mathrm{~mm}$ 
away from the infraorbital rim extent $[47,48]$. Two screw fixation points with a diameter of $1.5 \mathrm{~mm}$ were considered at the infraorbital rim region. All degrees of freedom (DOF) of the nodes around the screw head were constrained. The setup represented a classical cantilever bending test, and therefore, the rotational DOF around the implant was considered free, while the translational DOF was constrained along all axes.

The meshing method is an essential aspect of the FE analysis for design validation since it establishes the accuracy of the investigative results. All models were discretized using a global element size of $0.2 \mathrm{~mm}$. The elements were defined to be parabolic with square elements, i.e., each shell element has eight nodes. To avoid singularities, the configuration models were re-meshed to accomplish regular triangulation. In the area around the screw fixation points, the number of elements was refined and increased by 50 using an additional mesh control. For the rectangular and triangular pattern profile configurations, the mesh size was additionally specified with an element size of $0.01 \mathrm{~mm}$. In contrast, for the circular pattern, a refinement of the mesh size of $0.05 \mathrm{~mm}$ was adequate to avoid singularities. These element sizes were chosen based on the preliminary tests and convergence calculations. A sensitivity test was also run to find the best mesh size, which was found when the results showed that the mesh could not be changed by more than $1 \%$ across simulations using different mesh densities. The number of elements and nodes used for various design pattern profiles are illustrated in Table 1.

Table 1. The number of elements and nodes in various design pattern profiles.

\begin{tabular}{ccccc}
\hline & Solid & Rectangular & Triangular & Circular \\
\hline Number of elements & 18,883 & 26,806 & 31,915 & 26,474 \\
Number of nodes & 57,124 & 82,296 & 97,995 & 83,036 \\
\hline
\end{tabular}

The material properties were defined to be homogeneous, isotropic, and linearly elastic. According to the experimental data in a previous study for characterized properties of PEEK [49], the density of $1.30 \mathrm{~g} / \mathrm{cm}^{3}$ with the yield strength of $107.1 \mathrm{MPa}$ was taken, the Young's modulus was set to $4100 \mathrm{MPa}$, and the Poisson's ratio of 0.38 was used. The $\mathrm{FE}$ analyses were performed, and deformation (in $\mathrm{mm}$ ) was evaluated along the $\mathrm{X}, \mathrm{Y}$, and $\mathrm{Z}$ coordinates. Additionally, the von Mises stress was evaluated for each implant profile configuration.

\subsection{Additive Manufacturing Processes for PEEK Orbital Mesh Implants}

The thin orbital mesh implants were fabricated using a material extrusion-based FFF desktop 3D printer, designed specifically for PEEK medical additive manufacturing. The PEEK 3D printer (Apium M220, Apium Additive Technologies GmbH, Karlsruhe, Germany) is designed to generate PSIs in a hospital setting following the International Organization for Standardization (ISO) 10,993 series of requirements for the biological assessment of medical series [50]. The printer includes a temperature control system that offers an enclosed heated environment around the part during the layer-by-layer manufacturing process. The orbital mesh implants were fabricated using a medical-grade $1.75 \mathrm{~mm}$ PEEK filament extruded from Vestakeep ${ }^{\circledR}$ i4 G resin (Evonik Vestakeep ${ }^{\circledR}$ i4 G resin, Evonik Industries AG, Essen, Germany). This is a high viscosity, natural-colored, and implant-grade material widely used for long-term implantation and fulfills the requirement of the American Society for Testing and Materials (ASTM) F2026-17 guideline for PEEK polymers surgical implant applications [51].

For the fabrication process, the STL files of the designed implant profile configurations were imported into a slicing software (Simplify 3D version 4.0, Cincinnati, OH, USA) compatible with the 3D printer. Due to the complex geometry of the implants, the FFF printing process adds support structures underneath the overhangs and unsupported features. The initial attempts to print the PEEK orbital mesh implants with support structures resulted in poor printability and defective parts. Therefore, a different approach was adopted to fabricate the implants in various design configurations. 
We implemented a reversed-origami approach by converting the 3D CAD implant shape into a flattened 2D structure (Figure 5). To transfer the model into 2D space, an angular point on the implant surface was selected, and the "unwrap" functionality was used (Autodesk Inventor v. 2020 for Windows, Autodesk Inc., San Rafael, CA, USA). Subsequently, the resulting surface was extruded by the "thickness/offset" function for the selected thickness profile. The flattened implant profile configurations were then printed without any support structures. After printing, the implants were manually separated from the printed raft, and no further post-processing procedures were conducted.

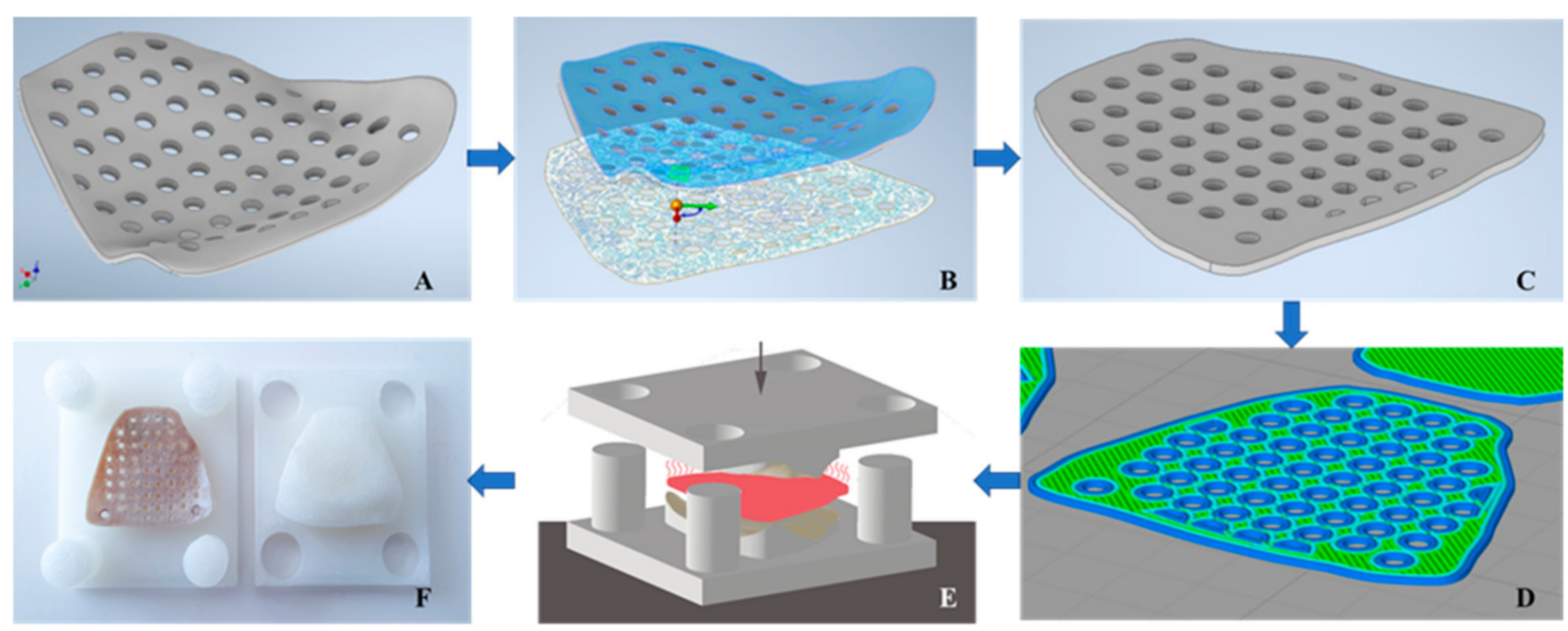

Figure 5. Schematic representation of the workflow implementing a reversed-origami approach for conversion of threedimensional (3D) computer-aided design implant shape into a 2D structure and 3D printing processes for conversion into a patient-specific orbital mesh implant. (A) 3D CAD implant design. (B) Unwrapping of the implant's 3D surface to 2D. (C) Thickness offset for the respective implant profile configuration. (D) G-code generation with selected printing parameters.

(E) Thermoforming process. (F) Patient-specific 3D PEEK orbital mesh implant.

A mold and a press box were created to convert these flattened printed implant configurations back into 3D orbital mesh forms. A lower mold representing the orbital floor plane as its surface and an upper mold with the negative of the orbital floor plane as its counterpart were designed. Finally, a rectangular press box with circular fitting connections was created to assemble the two mold pieces in a rotation- and displacement-free manner. The two-component mold and press-box were fabricated in 3D printed nylon material using a FFF desktop 3D printer (Original Prusa i3 MK3S, Prague, Czech Republic).

Each flattened printed implant was then heated with a hot air gun at $250-300{ }^{\circ} \mathrm{C}$ for $5 \mathrm{~min}$ to allow easier thermoforming. To prevent structural damage to the implant, it was essential to keep the temperature below PEEK's melting point of $343^{\circ} \mathrm{C}$ [52]. The heated implant was then inserted into the 2-component mold, and the press-box was compressed in a hydropulser at $0.5 \mathrm{MPa}$. Once cooled down to room temperature, the thin PEEK orbital mesh implant, now formed into a patient-specific 3D designed shape, was removed from the press box. An oral and maxillofacial surgeon independently evaluated the overall visual and tactile fit of the thermoformed PEEK mesh implants in terms of clinical appropriateness for possible orbital floor fracture repair. This evaluation was further quantified into four distinct grades: (1) poor, (2) satisfactory, (3) good, (4) excellent.

\subsection{Multi-Criteria Decision-Making (MCDM)—Configuration Assessment}

To achieve a conclusive result, a performance score for each configuration was devised. Each implant profile configuration was analyzed in terms of stress intensity, deformation, and morphological fit. A weighted assessment factor (AF) was developed to combine the above-mentioned constituent criteria as a metric. This factor was developed using a multi-criteria decision-making (MCDM) method called as Weight Sum Method (WSM) [46]. 
The stress intensity, deformation patterns, and the morphological fit of the implant were taken as $n$ criteria $(C)(C j$ for $j=1,2,3, \ldots n)$, while the alternatives $(A)$ were formed by $m$ possibilities $\left(A_{i}\right.$ for $\left.i=1,2, \ldots m\right)$ according to the pattern profile and thickness value of the implants. The following equation calculated the WSM-score of the i-th alternative:

$$
\mathrm{AF}_{\mathrm{i}}=\sum_{\mathrm{j}=1}^{\mathrm{N}} \mathrm{w}_{\mathrm{j}} \cdot \mathrm{y}_{\mathrm{ij}}
$$

where $A F_{i}$ is the assessment factor of the $i$-th alternative, $w_{j}$ is the weighting factor of the $j$-th criterion, $y_{i j}$ is the value of the $i$-th alternative for the $j$-th criterion. As these criteria have different analysis units, the result values were normalized by a linear max-min normalization method [53], as illustrated in the following formula:

$$
\frac{r_{j}^{\max }-r_{i j}}{r_{j}^{\max }-r_{j}^{m_{i} n}}
$$

where $r_{i j}$ describes the score of the $i$-th alternative for the $j$-th criterion. $r_{j} \max$ describes the maximum value of a criterion, and $r_{j}$ min , the corresponding minimum value. Considering a linear relationship between the normalized values and the actual values, the worst value of $C j$ is assigned a value of 0 , and the best value of $C j$ is assigned a value of 1 . After normalization, a weighting factor $(w)$ was assigned to each criterion, which was defined as:

$$
\mathrm{w}_{\mathrm{j}}=\frac{1}{\mathrm{n}}
$$

The value of each criterion is substantial, and the weighting variables were carefully determined with their total equal to 1 . All criteria were deemed to be equally essential, and therefore, in this study, the weighting factors of 0.33 were considered. Lastly, the assessment factor for each implant profile configuration was also normalized by the mean value of all AFs and their standard deviation (SD) for the final comparison using the following equation:

$$
\mathrm{AF}_{\mathrm{i}}^{*}=\frac{\mathrm{AF}_{\mathrm{i}}-\mu}{\sigma}
$$

where $\mu$ is the AF mean value within the implant profile configuration, and $\sigma$ is the SD of the assessment factors. The implant profile with the best configuration was represented with a positive $\mathrm{AF}_{\mathrm{i}}{ }^{*}$ and the worst configurations were represented with a negative $\mathrm{AF}_{\mathrm{i}}{ }^{*}$ value.

\section{Results}

Various profile configurations for thin PEEK orbital mesh implants were modeled, simulated, and 3D printed. The results were analyzed for the following quantitative and qualitative criteria, i.e., stress intensity, deformation patterns, and morphological fit of the implants. Utilizing the MCDM technique, the normalized $\mathrm{AF}_{\mathrm{i}}{ }^{*}$ for each implant profile configuration was then calculated to represent the performance score. The $\mathrm{AF}_{\mathrm{i}}{ }^{*}$ value depicted the implant profile configurations, i.e., a higher value of $\mathrm{AF}_{\mathrm{i}}{ }^{*}$ indicated a higher performance score. The individual values of the assessed criteria are reported in the following sections.

\subsection{Stress Intensity Patterns in the Thin PEEK Orbital Mesh Implants}

The maximum von Mises stress values in the implants ranged from 1.519 to $5.31 \mathrm{MPa}$. The typical von Mises stress distribution for the different implant profile configurations is illustrated in Table 2. The thinnest implant profiles resulted in the highest stress values. The highest and the lowest values of maximum von Mises stress were observed in R05 and C09, respectively (Figure 6). The stress intensity plots showed varying levels depending on the design pattern. The stress distribution in the rectangular patterned implants was most 
pronounced, while in triangular and circular patterned implants, similar distribution was noticed in all, except $0.5 \mathrm{~mm}$ profile implants.

Table 2. Stress and deformation pattern in various implant profile configurations.

\begin{tabular}{ccc}
\hline Implant Profile Configuration & Max. Von Mises $\mathbf{( M P a )}$ & Max. Deformation $(\mathbf{m m})$ \\
\hline R05 & 5.313 & 0.098 \\
R06 & 3.821 & 0.066 \\
R07 & 3.104 & 0.047 \\
R08 & 2.563 & 0.035 \\
R09 & 2.147 & 0.027 \\
T05 & 4.502 & 0.093 \\
T06 & 3.304 & 0.063 \\
T07 & 2.522 & 0.045 \\
T08 & 1.986 & 0.033 \\
T09 & 1.636 & 0.026 \\
C05 & 5.267 & 0.107 \\
C06 & 3.397 & 0.072 \\
C07 & 2.439 & 0.052 \\
C08 & 1.904 & 0.038 \\
C09 & 1.519 & 0.030 \\
\hline
\end{tabular}

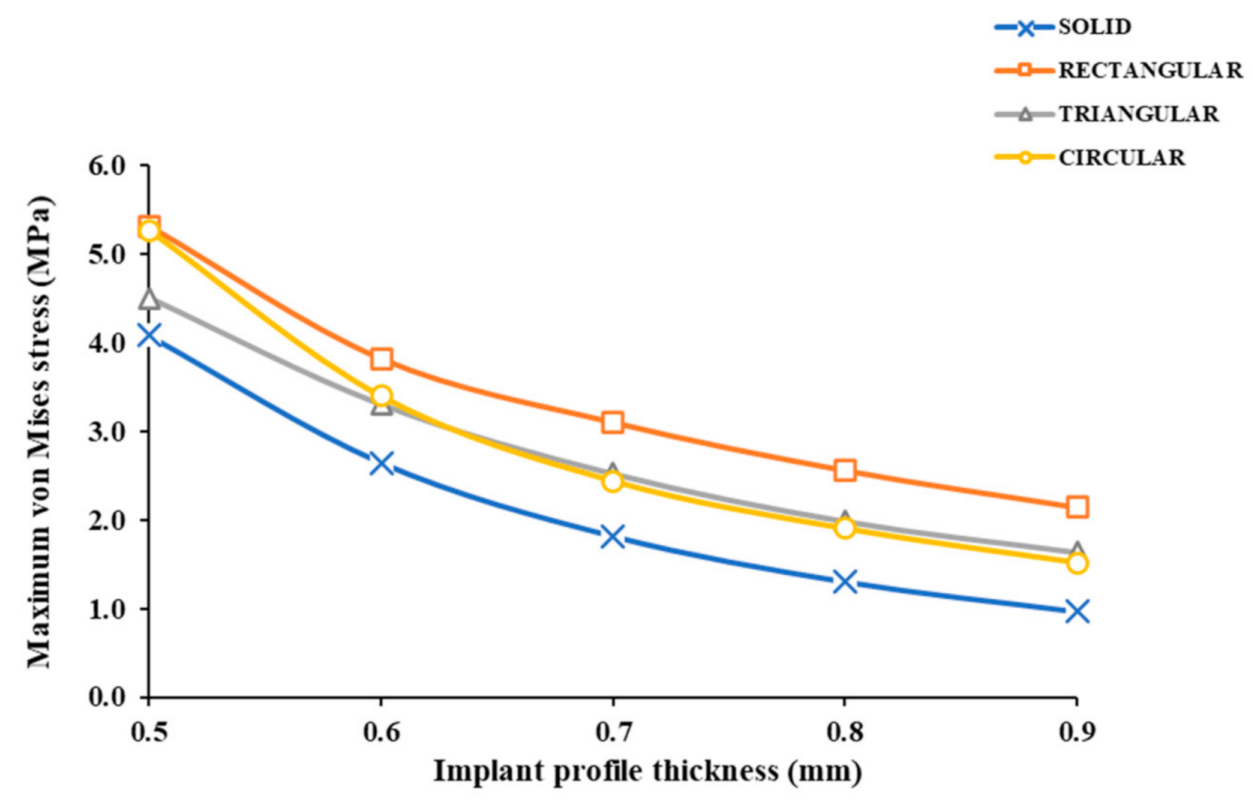

Figure 6. Maximum von Mises stress intensity $(\mathrm{MPa})$ values within each implant profile configuration.

\subsection{Deformation Patterns in the Thin PEEK Orbital Mesh Implants}

The deformation values in various implant profile configurations ranged from 0.026 to $0.107 \mathrm{~mm}$, as illustrated in Table 2. Figure 7A illustrates a magnified view displaying the evident orbital implant deformation in a solid implant (reference) profile. The highest and the lowest values for deformation were observed in $\mathrm{C} 05$ and $\mathrm{T} 09$ configurations, respectively (Figure 7B). It was noticed that with increasing implant thickness, the deformation became less pronounced. All the mesh implants deformed in an anti-clockwise manner with a downward displacement (Z-direction). The deformation was most pronounced at the posterior extent of the implant. 

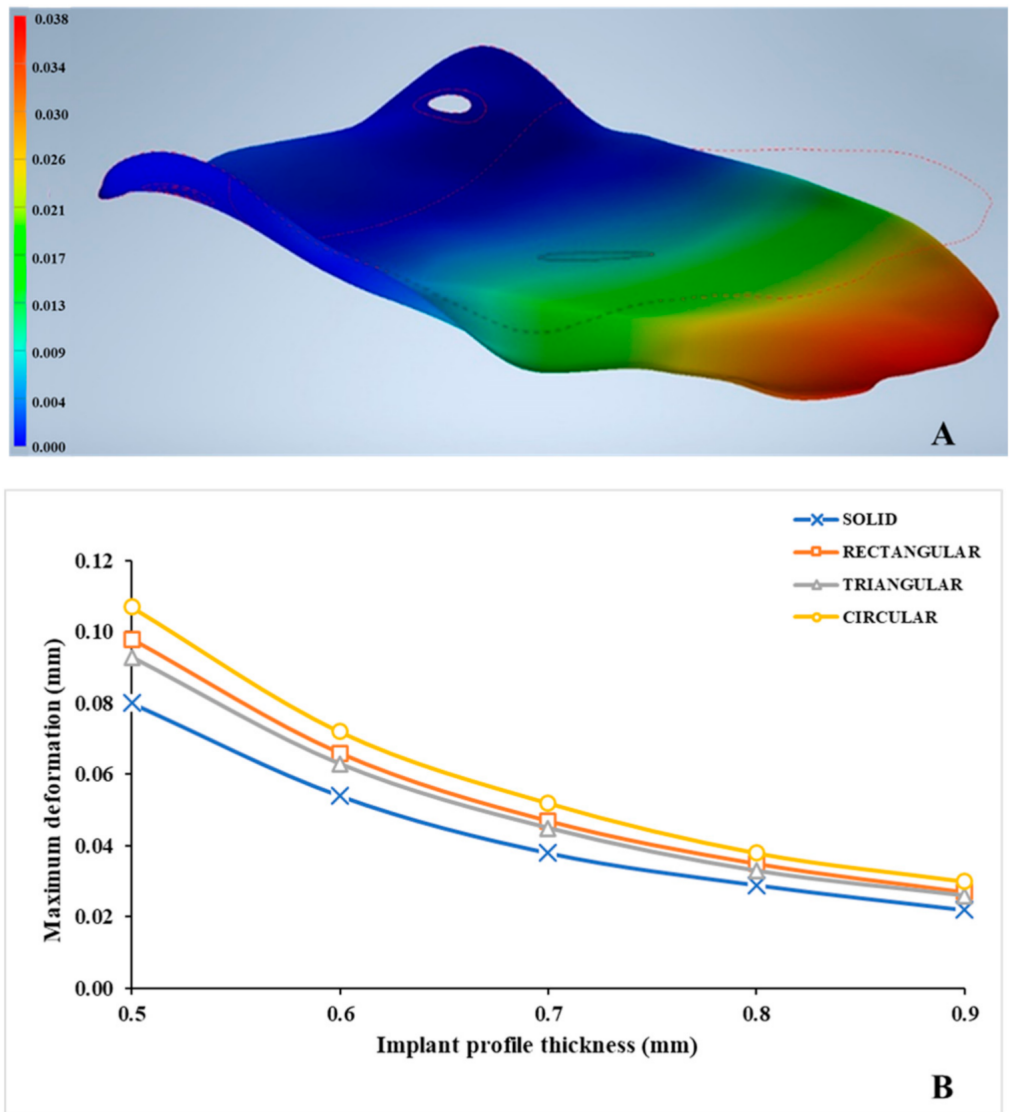

Figure 7. Deformation patterns in the PEEK customized orbital implants. (A) Deformation (mm) in a solid (reference) PEEK orbital implant. (B) Maximum deformation ( $\mathrm{mm}$ ) within each implant profile configuration.

\subsection{Morphological Assessment of the Thin PEEK Orbital Mesh Implants}

The morphological assessment for the overall fit of various implant profile configurations is illustrated in Figure 8. It was noticed that in all the design patterns, implants with a thickness profile of $\geq 0.7 \mathrm{~mm}$ had a higher grade. R07, T09, and C07 profile configurations displayed the highest score with a "good" (3;20\%) grade. The morphological fit of most of the implant profile configurations was rated as "satisfactory" $(8 ; 53.3 \%)$ or poor $(4 ; 26.6 \%)$.

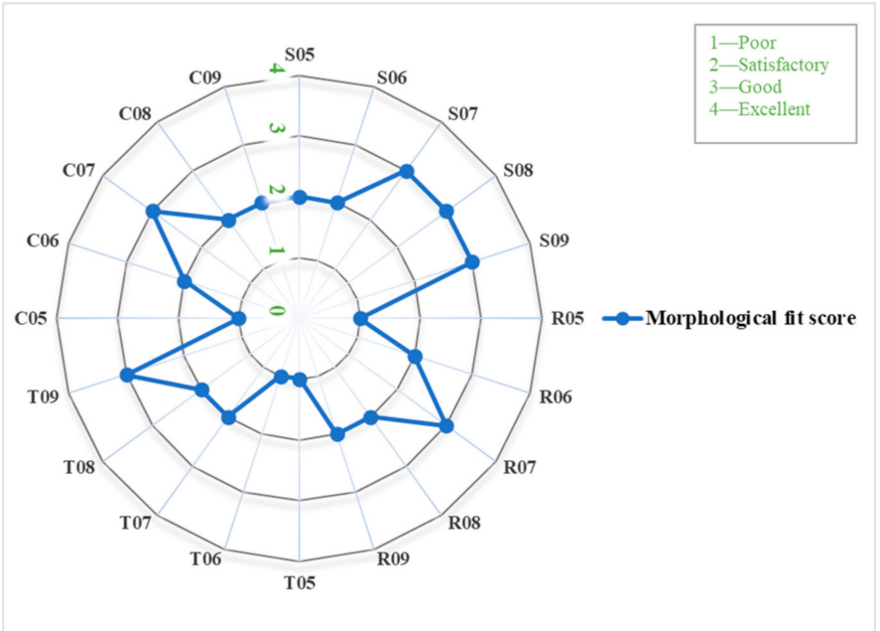

Figure 8. Polar plot representing the morphological fit score (1 to 4) within each implant profile configuration. 


\subsection{Configuration Assessment Using Multi-Criteria Decision Making (MCDM) Approach}

The computed $\mathrm{AF}_{\mathrm{i}}{ }^{*}$ value for each implant profile configuration is illustrated in Figure 9. It was noticed that in all the design patterns, implants with a thickness profile of $\geq 0.8 \mathrm{~mm}$ had a better performance score with a positive $\mathrm{AF}_{\mathrm{i}}{ }^{*}$ value. All but a $0.5 \mathrm{~mm}$ thickness profile revealed a positive $\mathrm{AF}_{\mathrm{i}}{ }^{*}$ value in the triangular patterned implants. The best and worst implant profile configurations, based on $\mathrm{AF}_{\mathrm{i}}{ }^{*}$ value, were $\mathrm{C} 09$ and $\mathrm{C} 05$, respectively. Figure 10 illustrates the stress intensity and deformation plot for the best implant profile configuration.

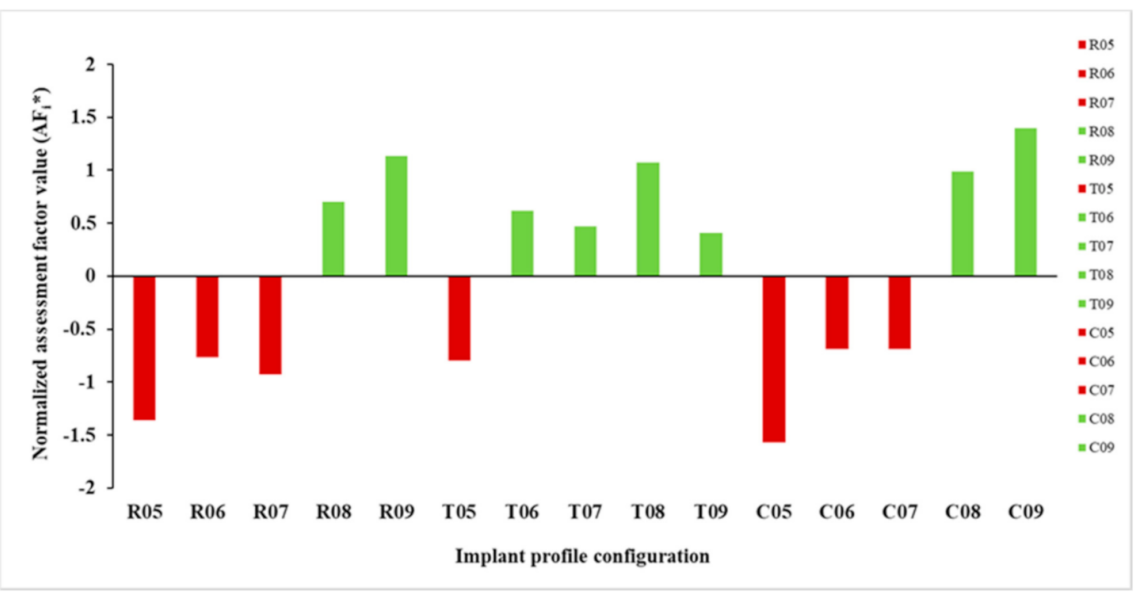

Figure 9. Normalized assessment factors $\left(\mathrm{AF}_{\mathrm{i}}{ }^{*}\right)$ within each implant profile configuration.

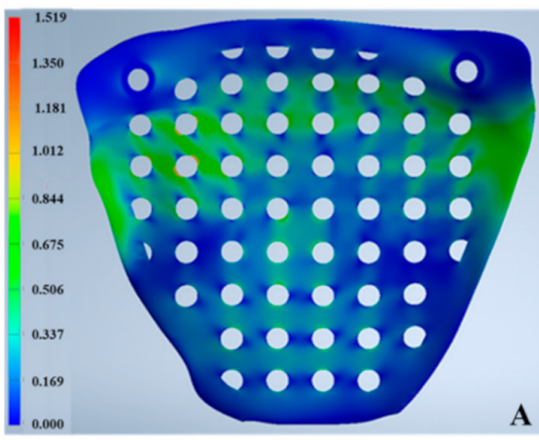

C09: Element stresses (MPa, von Mises)

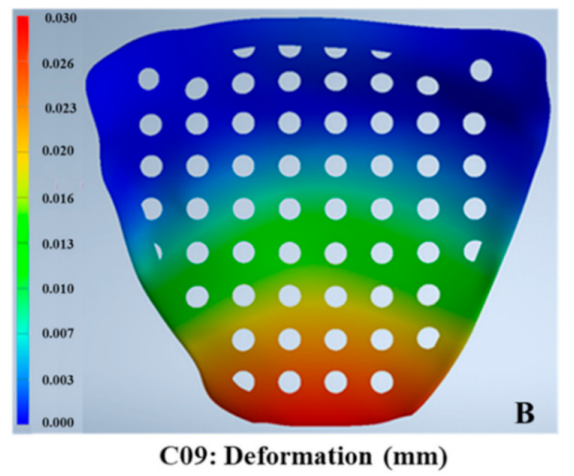

C09: Deformation (mm)

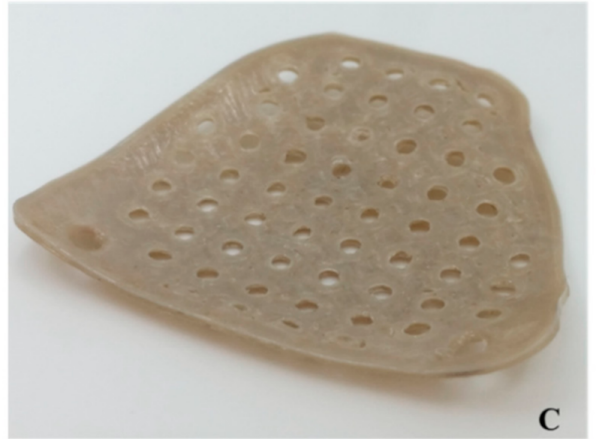

C09: FFF 3D printed PEEK orbital mesh implant

Figure 10. Orbital implant profile configuration with the best performance score. (A) C09 stress intensity (MPa) plot. (B) C09 deformation (mm) plot. (C) C09 material extrusion-based 3D printed PEEK orbital mesh implant.

\section{Discussion}

The advanced capabilities of 3D CAD modeling and printing technology are changing a wide range of medical specialties, with craniomaxillofacial surgery being one of the 
most significant benefactors. Custom-made or PSIs are now accessible for various clinical scenarios, allowing for better functional and esthetic outcomes with less surgical time and no donor site morbidity [54]. The use of PEEK PSIs in cranial reconstructions is well documented in the literature, with a trend toward lower implant failure rates with PEEK versus titanium mesh [55]. Furthermore, PEEK PSIs have also been used in craniofacial defects reconstruction [56], in midface reconstruction as an alternative to composite free tissue transfer or maxillary obturators $[57,58]$. In addition, PEEK onlay implants have been utilized in zygoma contour augmentation [31,32] and mandibular angle reconstructive surgeries [59]. While the use of CAD/CAM milled PEEK orbital implants have been documented in the literature $[60,61]$, the production of porous, mesh-like orbital implants by FFF is relatively new. With improvement in AM systems, the potential for customized FFF 3D printed PEEK implants has surfaced, boosting interest in POC manufacturing [25,26,30].

The development of PSIs at the POC requires the construction of a complete in-house digital workflow. Here, we implemented clinical experience and engineering principles to generate a technical roadmap from preoperative CT datasets, to VSP, to computational models of various design variants, to the fabrication of PEEK PSIs using FFF 3D printing technology. More specifically, a clinical case with patient-specific PEEK orbital reconstruction was evaluated under $0.3 \mathrm{~N}$ static load. We then assessed the performance of each implant profile configuration through the WSM-based assessment criteria.

To evaluate the performance of each implant profile configuration, the mechanical response regarding stress and deformation patterns were observed. The maximum von Mises stresses observed in the configurations were in the range of 1.519 to $5.313 \mathrm{MPa}$. Different stress intensity plots were noticed with increasing implant thickness and changing patterns; however, these differences were not substantial. Although assessing the limit states (e.g., yielding, fatigue) was outside the scope of this study, it is worth noting that stress peak values in all the implant profile configurations were below the assumed material's yield (failure) stress value (107 MPa). The maximum stress values achieved in our results predict the high durability of the implants, and none of the implant profile configurations exceeded this permissible limit.

In all implant profile configurations, the maximum deformation values were largely under one-tenth of a millimeter (mm). Only one implant profile configuration showed large deformation of $0.107 \mathrm{~mm}$ (C05). The individual results revealed that the implant thickness is the most significant factor affecting the stress and deformation patterns in all evaluated configurations. On the contrary, the design patterns had more effect from the fabrication point of view affecting the morphological characteristics. Signs of inaccurate pattern shape were observed in a triangular patterned design. It can be ascertained that the manufacturing process significantly influences the clinical applicability of an implant. The thinner implants, i.e., $<0.7 \mathrm{~mm}$, had less thermoforming time and all the implants retained their shape after thermoforming. The assessment factor helped differentiate between configurations and resulted in a composite assessment based on performance score. Furthermore, it was noticed that regardless of the implant thicknesses, the thermoformed PEEK mesh implants maintain the patient-specific shape, and recontouring can only be achieved when reheated up to $300^{\circ} \mathrm{C}$. As PEEK is a high-temperature thermoplastic biomaterial with good mechanical strength, rigidity, stiffness, and dimensional stability properties $[19,27,29,33]$, the insertion process during surgery must prevent deformation of the mesh contour. During the insertion process, the PEEK mesh implants may require rotation to be adequately positioned for a stable recontouring of the orbital walls. Therefore, adequate retraction of the intra-orbital soft tissues, with no orbital fat or muscles entrapment, should be achieved.

Even though FFF appears to be a straightforward procedure, achieving high efficiency and high-quality manufacturing outputs in PEEK printing presents considerable hurdles $[25,43]$. Studies have shown that the amount of crystallinity of PEEK material influences its mechanical characteristics. Increasing the crystallinity of a PEEK component can enhance its elastic modulus and yield strength [62]. It was noticed that all the implant profile configurations displayed optimal crystallinity with no visible signs of amorphous 
(dark-colored) regions. Due to the inherent printing mechanism of FFF, another aspect that needs to be considered is the support structures. The fabrication of thin, complex-shaped PEEK implants with support structures contributes to extensive post-processing procedures and results in a rougher implant surface. This aspect can limit the clinical applicability of an implant. Therefore, an alternative approach was considered in this study to manufacture implants with minimal post-processing and without any support structures. The results in our study validate that a straightforward thermoforming procedure can be applied for PEEK customized mesh implants.

Although AM offers design freedom meaning that very complex designs are feasible to manufacture, the printing mechanism of the selected AM technology is often a decisive factor. A specific design for one AM technology might not be suitable for another printing technology. Therefore, principles of design for AM (DfAM) must always be taken into consideration. Design for AM (DfAM) methods seek to fully exploit the inherent functionalities of a printing technology resulting in improved performance of biomaterials. Several unseen combinations with beneficial properties can be generated, resulting in sophisticated geometrical designs [63-66]. We implemented an "infill-based" approach to fabricate the PEEK customized orbital mesh implant to comprehend this aspect further. A g-code based tool path was created using the orbital implant STL file with no pattern. The in-built infill-pattern functionality in the slicing software was used. Figure 11 illustrates a $0.7 \mathrm{~mm}$ orbital PEEK mesh implant fabricated using the rectangular infill pattern. This paradigm represents the applicability of in-built printing functionalities and motivates further research to investigate the intrinsic FFF 3D printing characteristics.

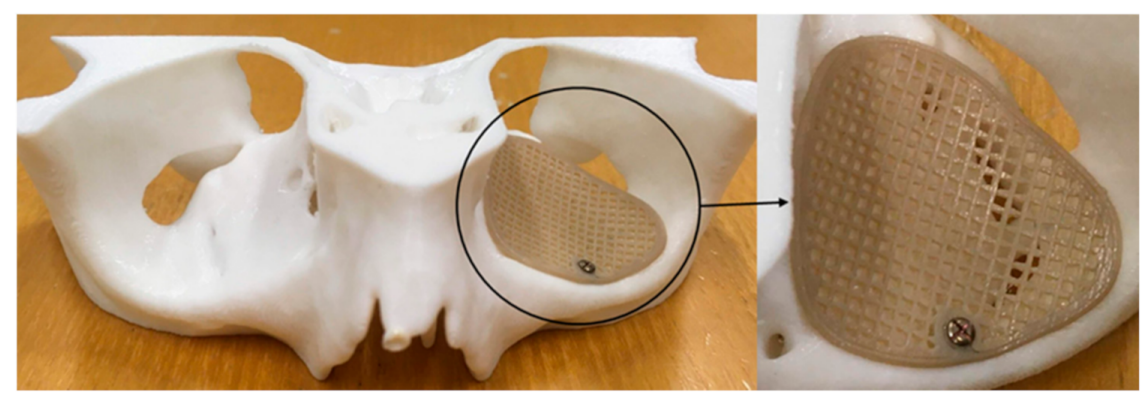

Figure 11. 3D printed biomodel with material extrusion-based 3D printed PEEK orbital mesh implant $(0.7 \mathrm{~mm})$ fabricated using the rectangular infill pattern.

The study limitations include simplification of the FE computational model. The use of nonlinear analyses and volume elements was initially computed in this study. However, the results did not reveal significant differences compared to the linear static analysis. Therefore, considering short computational time, linear static analyses were used, which is helpful for a faster comparison of various implant profile configurations. Another significant area of concern is the anchoring capabilities of the fixation screws and the intrinsic heterogeneity in bone quality $[67,68]$. Substantial high stresses at the screw-bone interface can jeopardize the overall implant stability. Such an estimation of the implant profile configurations would require detailed analysis, particularly at the component interfaces. Therefore, the FE analysis in our study represents a nominal value. However, considering the study objective, the simulation setup in this work, on the other hand, demonstrates an effective technique in the relative evaluation of various design profiles while avoiding complicated model setup and computational cost. Moreover, the approach can be further improved by integrating anisotropic material characteristics of FFF 3D printed parts. Furthermore, we confined the research variables to three criteria; however, the weighting factors can be further tailored to the unique requirements of the analysis. Lastly, we evaluated the performance in one clinical scenario case; further studies are needed to assess the performance in defects with increasing complexity. 


\section{Conclusions}

With CAD and 3D printing, multiple treatment options can be devised. An implant for orbital floor reconstruction should minimize the extreme stresses and deformation under physiological conditions and have optimal printing characteristics from a clinical perspective. The study provides insights into the concept of POC FFF 3D printing of PEEK orbital mesh customized implants. Using MCDM, FE-based computational analysis, and FFF 3D printing can be evaluated in multiple treatment options. This approach demonstrates that a range of combinations can be assessed to reach the most effective clinical solution.

Author Contributions: Conceptualization, N.S. and F.M.T.; methodology, N.S. and D.W.; software, N.S. and D.W.; validation, N.S.; visualization, N.S., T.S. and F.M.T.; formal analysis, N.S. and S.A.; investigation, N.S. and D.W.; resources, P.H. and F.M.T.; data curation, N.S. and D.W.; writingoriginal draft preparation, N.S.; writing—review and editing, N.S., D.W., S.A., M.M., H.-F.Z., P.H., T.S, and F.M.T.; supervision, T.S. and F.M.T.; and project administration, H.-F.Z. and F.M.T. All authors have read and agreed to the published version of the manuscript.

Funding: The open-access article processing charges were paid by the Section of Dental Medicine and Craniomaxillofacial Surgery, Center of Competence for Military and Disaster medicine, Swiss Army. The Werner Siemens Foundation funded this research project.

Institutional Review Board Statement: Not applicable.

Informed Consent Statement: Not applicable.

Data Availability Statement: The original contributions presented in the study are included in the article, further inquiries can be directed to the corresponding author.

Acknowledgments: This study is part of the MIRACLE (Minimally Invasive Robot-Assisted Computerguided LaserostetomE) project.

Conflicts of Interest: The authors declare no conflict of interest.

$\begin{array}{ll}\text { Abbreviation } & \\ \text { 2D } & \text { Two-Dimensional } \\ \text { 3D } & \text { Three-Dimensional } \\ \text { AF } & \text { Assessment Factor } \\ \text { AM } & \text { Additive Manufacturing } \\ \text { ASTM } & \text { American Society for Testing and Materials } \\ \text { CAD } & \text { Computer-Aided Design } \\ \text { CAM } & \text { Computer-Aided Manufacturing } \\ \text { CAS } & \text { Computer-Assisted Surgery } \\ \text { CT } & \text { Computed Tomography } \\ \text { DfAM } & \text { Design for Additive Manufacturing } \\ \text { DICOM } & \text { Digital Imaging and Communications in Medicine } \\ \text { DOF } & \text { Degree of Freedom } \\ \text { FE } & \text { Finite Element } \\ \text { FFF } & \text { Fused Filament Fabrication } \\ \text { ISO } & \text { International Organization for Standardization } \\ \text { MCDM } & \text { Multi-Criteria Decision Making } \\ \text { PEEK } & \text { Polyetheretherketone } \\ \text { POC } & \text { Point-of-Care } \\ \text { PSIs } & \text { Patient Specific Implants } \\ \text { ROI } & \text { Region of Interest } \\ \text { SD } & \text { Standard Deviation } \\ \text { STL } & \text { Standard Tessellation Language } \\ \text { VSP } & \text { Virtual Surgical Planning } \\ \text { WSM } & \text { Weight Sum Method }\end{array}$




\section{References}

1. Smith, B.; Regan, W.F., Jr. Blow-out fracture of the orbit; mechanism and correction of internal orbital fracture. Am. J. Ophthalmol. 1957, 44, 733-739. [CrossRef]

2. Ahmad Nasir, S.; Ramli, R.; Abd Jabar, N. Predictors of enophthalmos among adult patients with pure orbital blowout fractures. PLOS ONE 2018, 13, e0204946. [CrossRef] [PubMed]

3. Hwang, K.; You, S.H.; Sohn, I.A. Analysis of orbital bone fractures: A 12-year study of 391 patients. J. Craniofac. Surg. 2009, 20, 1218-1223. [CrossRef]

4. Boyette, J.R.; Pemberton, J.D.; Bonilla-Velez, J. Management of orbital fractures: Challenges and solutions. Clin. Ophthalmol. 2015, 9, 2127-2137. [CrossRef]

5. Parameswaran, A.; Marimuthu, M.; Panwar, S.; Hammer, B. Orbital Fractures. In Oral and Maxillofacial Surgery for the Clinician, 1st ed.; Bonanthaya, K., Panneerselvam, E., Manuel, S., Kumar, V.V., Rai, A., Eds.; Springer: Singapore, 2021; pp. 1201-1250.

6. Gunarajah, D.R.; Samman, N. Biomaterials for repair of orbital floor blowout fractures: A systematic review. J. Oral Maxillofac. Surg. 2013, 71, 550-570. [CrossRef]

7. Baumann, A.; Sinko, K.; Dorner, G. Late reconstruction of the orbit with patient-specific implants using computer-aided planning and navigation. J. Oral Maxillofac. Surg. 2015, 73, S101-S106. [CrossRef]

8. Hwang, K.; Kim, D.H. Comparison of the supporting strength of a poly-L-lactic acid sheet and porous polyethylene (Medpor) for the reconstruction of orbital floor fractures. J. Craniofac. Surg. 2010, 21, 847-853. [CrossRef] [PubMed]

9. Romano, J.J.; Iliff, N.T.; Manson, P.N. Use of Medpor porous polyethylene implants in 140 patients with facial fractures. J. Craniofac. Surg. 1993, 4, 142-147. [CrossRef]

10. Mommaerts, M.; Büttner, M.; Vercruysse, H., Jr.; Wauters, L.; Beerens, M. Orbital wall reconstruction with two-piece puzzle 3d printed implants: Technical note. Craniomaxillofac. Trauma Reconstr. 2016, 9, 55-61. [CrossRef] [PubMed]

11. Dubois, L.; Jansen, J.; Schreurs, R.; Saeed, P.; Beenen, L.; Maal, T.J.; Gooris, P.J.; Becking, A.G. Predictability in orbital reconstruction: A human cadaver study. Part I: Endoscopic-assisted orbital reconstruction. J. Craniomaxillofac. Surg. 2015, 43, $2034-2041$. [CrossRef]

12. Kunz, C.; Audigé, L.; Cornelius, C.; Buitrago-Téllez, C.; Rudderman, R.; Prein, J. The comprehensive AOCMF classification system: Orbital fractures—Level 3 tutorial. Craniomaxillofac. Trauma Reconstr. 2014, 7, S92-S102. [CrossRef] [PubMed]

13. Dubois, L.; Schreurs, R.; Jansen, J.; Maal, T.J.; Essig, H.; Gooris, P.J.; Becking, A.G. Predictability in orbital reconstruction: A human cadaver study. Part II: Navigation-assisted orbital reconstruction. J. Craniomaxillofac. Surg. 2015, 43, 2042-2049. [CrossRef]

14. Dubois, L.; Essig, H.; Schreurs, R.; Jansen, J.; Maal, T.J.; Gooris, P.J.; Becking, A.G. Predictability in orbital reconstruction. A human cadaver study, part III: Implant-oriented navigation for optimized reconstruction. J. Craniomaxillofac. Surg. 2015, 43, 2050-2056. [CrossRef] [PubMed]

15. Schreurs, R.; Dubois, L.; Becking, A.G.; Maal, T.J. Quantitative Assessment of Orbital Implant Position-A Proof of Concept. PLoS ONE 2016, 11, e0150162. [CrossRef]

16. Dubois, L.; Steenen, S.A.; Gooris, P.J.J.; Mourits, M.P.; Becking, A.G. Controversies in orbital reconstruction-II. Timing of post-traumatic orbital reconstruction: A systematic review. Int. J. Oral Maxillofac. Surg. 2015, 44, 433-440. [CrossRef] [PubMed]

17. Gander, T.; Essig, H.; Metzler, P.; Lindhorst, D.; Dubois, L.; Rücker, M.; Schumann, P. Patient specific implants (PSI) in reconstruction of orbital floor and wall fractures. J. Craniomaxillofac. Surg. 2015, 43, 126-130. [CrossRef]

18. Rana, M.; Chui, C.H.; Wagner, M.; Zimmerer, R.; Rana, M.; Gellrich, N.C. Increasing the accuracy of orbital reconstruction with selective laser-melted patient-specific implants combined with intraoperative navigation. J. Oral Maxillofac. Surg. 2015, 73, 1113-1118. [CrossRef] [PubMed]

19. Chepurnyi, Y.; Chernogorskyi, D.; Kopchak, A.; Petrenko, O. Clinical efficacy of peek patient-specific implants in orbital reconstruction. J. Oral Biol. Craniofac. Res. 2020, 10, 49-53. [CrossRef]

20. Sigron, G.R.; Rüedi, N.; Chammartin, F.; Meyer, S.; Msallem, B.; Kunz, C.; Thieringer, F.M. Three-Dimensional Analysis of Isolated Orbital Floor Fractures Pre- and Post-Reconstruction with Standard Titanium Meshes and "Hybrid" Patient-Specific Implants. J. Clin. Med. 2020, 9, 1579. [CrossRef] [PubMed]

21. Baino, F. Biomaterials and implants for orbital floor repair. Acta Biomater. 2011, 7, 3248-3266. [CrossRef]

22. Avashia, Y.J.; Sastry, A.; Fan, K.L.; Mir, H.S.; Thaller, S.R. Materials used for reconstruction after orbital floor fracture. J. Craniofac. Surg. 2012, 23, S49-S55. [CrossRef]

23. Mok, D.; Lessard, L.; Cordoba, C.; Harris, P.G.; Nikolis, A. A review of materials currently used in orbital floor reconstruction. Can. J. Plast Surg. 2004, 12, 134-140. [CrossRef]

24. Gu, R.D.; Xiao, F.; Wang, L.; Sun, K.J.; Chen, L.L. Biocompatibility of polyetheretherketone for the treatment of orbital bone defects. Int. J. Ophthalmol. 2020, 13, 725-730. [CrossRef] [PubMed]

25. Sharma, N.; Aghlmandi, S.; Cao, S.; Kunz, C.; Honigmann, P.; Thieringer, F.M. Quality Characteristics and Clinical Relevance of In-House 3D-Printed Customized Polyetheretherketone (PEEK) Implants for Craniofacial Reconstruction. J. Clin. Med. 2020, 9, 2818. [CrossRef] [PubMed]

26. Honigmann, P.; Sharma, N.; Schumacher, R.; Rueegg, J.; Haefeli, M.; Thieringer, F. In-Hospital 3D Printed Scaphoid Prosthesis Using Medical-Grade Polyetheretherketone (PEEK) Biomaterial. Biomed. Res. Int. 2021, 11, 1301028. [CrossRef]

27. Panayotov, I.V.; Orti, V.; Cuisinier, F.; Yachouh, J. Polyetheretherketone (PEEK) for medical applications. J. Mater. Sci. Mater. Med. 2016, 27, 118. [CrossRef] [PubMed] 
28. Han, X.; Sharma, N.; Xu, Z.; Scheideler, L.; Geis-Gerstorfer, J.; Rupp, F.; Thieringer, F.M.; Spintzyk, S. An In Vitro Study of Osteoblast Response on Fused-Filament Fabrication 3D Printed PEEK for Dental and Cranio-Maxillofacial Implants. J. Clin. Med. 2019, 8, 771. [CrossRef]

29. Basgul, C.; Spece, H.; Sharma, N.; Thieringer, F.M.; Kurtz, S.M. Structure, properties, and bioactivity of 3D printed PAEKs for implant applications: A systematic review. J. Biomed. Mater. Res. B Appl. Biomater. 2021. online ahead of print. [CrossRef]

30. Honigmann, P.; Sharma, N.; Okolo, B.; Popp, U.; Msallem, B.; Thieringer, F.M. Patient-Specific Surgical Implants Made of 3D Printed PEEK: Material, Technology, and Scope of Surgical Application. Biomed. Res. Int. 2018, 2018, 4520636. [CrossRef]

31. Nazimi, A.J.; Md Yusoff, M.; Nordin, R.; Nabil, S. Use of polyetheretherketone (PEEK) in orbital floor fracture reconstruction-A case for concern. J. Oral Maxillofac. Surg. Med. Pathol. 2015, 27, 536-539. [CrossRef]

32. Pedemonte Trewhela, C.; Díaz Reiher, M.; Muñoz Zavala, T.; González Mora, L.E.; Vargas Farren, I. Correction of Delayed Traumatic Enophthalmos Using Customized Orbital Implants. J. Oral Maxillofac. Surg. 2018, 76, 1937-1945. [CrossRef]

33. Kurtz, S.M.; Devine, J.N. PEEK biomaterials in trauma, orthopedic, and spinal implants. Biomaterials 2007, 28, 4845-4869. [CrossRef]

34. Johansson, P.; Jimbo, R.; Kjellin, P.; Currie, F.; Chrcanovic, B.R.; Wennerberg, A. Biomechanical evaluation and surface characterization of a nano-modified surface on PEEK implants: A study in the rabbit tibia. Int. J. Nanomed. 2014, 9, 3903-3911. [CrossRef] [PubMed]

35. Feng, X.; Ma, L.; Liang, H.; Liu, X.; Lei, J.; Li, W.; Wang, K.; Song, Y.; Wang, B.; Li, G.; et al. Osteointegration of 3D-Printed Fully Porous Polyetheretherketone Scaffolds with Different Pore Sizes. ACS Omega 2020, 5, 26655-26666. [CrossRef] [PubMed]

36. Zhang, J.; Wei, W.; Yang, L.; Pan, Y.; Wang, X.; Wang, T.; Tang, S.; Yao, Y.; Hong, H.; Wei, J. Stimulation of cell responses and bone ingrowth into macro-microporous implants of nano-bioglass/polyetheretherketone composite and enhanced antibacterial activity by release of hinokitiol. Colloids Surf. B 2018, 164, 347-357. [CrossRef] [PubMed]

37. Baştan, F.E.; Atiq Ur Rehman, M.; Avcu, Y.Y.; Avcu, E.; Üstel, F.; Boccaccini, A.R. Electrophoretic co-deposition of PEEKhydroxyapatite composite coatings for biomedical applications. Colloids Surf. B 2018, 169, 176-182. [CrossRef] [PubMed]

38. Spece, H.; Yu, T.; Law, A.W.; Marcolongo, M.; Kurtz, S.M. 3D printed porous PEEK created via fused filament fabrication for osteoconductive orthopaedic surfaces. J. Mech. Behav. Biomed. Mater. 2020, 109, 103850. [CrossRef]

39. Torstrick, F.B.; Safranski, D.L.; Burkus, J.K.; Chappuis, J.L.; Lee, C.S.D.; Guldberg, R.E.; Gall, K.; Smith, K.E. Getting PEEK to Stick to Bone: The Development of Porous PEEK for Interbody Fusion Devices. Tech. Orthop. 2017, 32, 158-166. [CrossRef]

40. Landy, B.C.; Vangordon, S.B.; McFetridge, P.S.; Sikavitsas, V.I.; Jarman-Smith, M. Mechanical and in vitro investigation of a porous PEEK foam for medical device implants. J. Appl. Biomater. Funct. Mater. 2013, 11, e35-e44. [CrossRef]

41. Wang, X.; Xu, S.; Zhou, S.; Xu, W.; Leary, M.; Choong, P.; Qian, M.; Brandt, M.; Xie, Y.M. Topological design and additive manufacturing of porous metals for bone scaffolds and orthopaedic implants: A review. Biomaterials 2016, 83, 127-141. [CrossRef]

42. Guddati, S.; Kiran, A.S.K.; Leavy, M.; Ramakrishna, S. Recent advancements in additive manufacturing technologies for porous material applications. Int. J. Adv. Manuf. Technol. 2019, 105, 193-215. [CrossRef]

43. Vaezi, M.; Yang, S. Extrusion-based additive manufacturing of PEEK for biomedical applications. Virtual Phys. Prototyp. 2015, 10, 123-135. [CrossRef]

44. Han, D.H.; Chi, M. Comparison of the outcomes of blowout fracture repair according to the orbital implant. J. Craniofac. Surg. 2011, 22, 1422-1425. [CrossRef] [PubMed]

45. El Halabi, F.; Rodriguez, J.F.; Rebolledo, L.; Hurtos, E.; Doblare, M. Mechanical characterization and numerical simulation of polyether-ether-ketone (PEEK) cranial implants. J. Mech. Behav. Biomed. Mater. 2011, 4, 1819-1832. [CrossRef] [PubMed]

46. Ridwan-Pramana, A.; Marcián, P.; Borák, L.; Narra, N.; Forouzanfar, T.; Wolff, J. Finite element analysis of 6 large PMMA skull reconstructions: A multi-criteria evaluation approach. PLoS ONE 2017, 12, e0179325. [CrossRef] [PubMed]

47. Guillaume, O.; Geven, M.A.; Varjas, V.; Varga, P.; Gehweiler, D.; Stadelmann, V.A.; Smidt, T.; Zeiter, S.; Sprecher, C.; Bos, R.R.M.; et al. Orbital floor repair using patient specific osteoinductive implant made by stereolithography. Biomaterials 2020, $233,119721$. [CrossRef]

48. Birkenfeld, F.; Behrens, E.; Kern, M.; Gassling, V.; Wiltfang, J. Mechanical properties of collagen membranes: Are they sufficient for orbital floor reconstructions? J. Craniomaxillofac. Surg. 2015, 43, 260-263. [CrossRef] [PubMed]

49. Rae, P.J.; Brown, E.N.; Orler, E.B. The mechanical properties of poly(etherether-ketone) (PEEK) with emphasis on the large compressive strain response. Polymer 2007, 48, 598-615. [CrossRef]

50. Garcia-Leiner, M.; Ghita, O.; McKay, R.; Kurtz, S. Additive Manufacturing of Polyaryletherketones. In PEEK Biomaterials Handbook, 2nd ed.; Kurtz, S., Ed.; William Andrew Publishing: New York, NY, USA, 2019; pp. 89-103.

51. Graham, J.; Peck, J. FDA Regulation of PEEK Implants. In PEEK Biomaterials Handbook, 2nd ed.; Kurtz, S., Ed.; William Andrew Publishing: New York, NY, USA, 2019; pp. 431-445.

52. Basgul, C.; Thieringer, F.M.; Kurtz, S.M. Heat transfer-based non-isothermal healing model for the interfacial bonding strength of fused filament fabricated polyetheretherketone. Addit. Manuf. 2021, 46, 102097. [CrossRef]

53. Jahan, A.; Edwards, K.L. A state-of-the-art survey on the influence of normalization techniques in ranking: Improving the materials selection process in engineering design. Mater. Des. 2015, 65, 335-342. [CrossRef]

54. Alasseri, N.; Alasraj, A. Patient-specific implants for maxillofacial defects: Challenges and solutions. Maxillofac. Plast. Reconstr. Surg. 2020, 42, 15. [CrossRef] 
55. Punchak, M.; Chung, L.K.; Lagman, C.; Bui, T.T.; Lazareff, J.; Rezzadeh, K.; Jarrahy, R.; Yang, I. Outcomes following polyetheretherketone (PEEK) cranioplasty: Systematic review and meta-analysis. J. Clin. Neurosci. 2017, 41, 30-35. [CrossRef]

56. Rammos, C.K.; Cayci, C.; Castro-Garcia, J.A.; Feiz-Erfan, I.; Lettieri, S.C. Patient-specific polyetheretherketone implants for repair of craniofacial defects. J. Craniofac. Surg. 2015, 26, 631-633. [CrossRef] [PubMed]

57. Järvinen, S.; Suojanen, J.; Kormi, E.; Wilkman, T.; Kiukkonen, A.; Leikola, J.; Stoor, P. The use of patient specific polyetheretherketone implants for reconstruction of maxillofacial deformities. J. Craniomaxillofac. Surg. 2019, 47, 1072-1076. [CrossRef] [PubMed]

58. Ding, L.; Chen, X.; Zhang, J.; Wang, R.; Wu, G. Digital fabrication of a maxillary obturator prosthesis by using a 3-dimensionallyprinted polyetheretherketone framework. J. Prosthet. Dent. 2021. [CrossRef]

59. Olate, S.; Uribe, F.; Huentequeo-Molina, C.; Goulart, D.R.; Sigua-Rodriguez, E.A.; Alister, J.P. Mandibular Angle Contouring Using Porous Polyethylene Stock or PEEK-based Patient Specific Implants. A Critical Analysis. J. Craniofac. Surg. 2021, 32, 242-246. [CrossRef]

60. Herford, A.S.; Miller, M.; Lauritano, F.; Cervino, G.; Signorino, F.; Maiorana, C. The use of virtual surgical planning and navigation in the treatment of orbital trauma. Chin. J. Traumatol. 2017, 20, 9-13. [CrossRef]

61. Chepurnyi, Y.; Chernogorskyi, D.; Petrenko, O.; Kopchak, A. Reconstruction of Post-Traumatic Orbital Defects and Deformities with Custom-Made Patient-Specific Implants: Evaluation of the Efficacy and Clinical Outcome. Craniomaxillofac. Trauma Reconstr. Open 2019, 3, e9-e17. [CrossRef]

62. Yang, C.; Tian, X.; Li, D.; Cao, Y.; Zhao, F.; Shi, C. Influence of thermal processing conditions in 3D printing on the crystallinity and mechanical properties of PEEK material. J. Mater. Process. Technol. 2017, 248, 1-7. [CrossRef]

63. Zadpoor, A.A. Design for Additive Bio-Manufacturing: From Patient-Specific Medical Devices to Rationally Designed MetaBiomaterials. Int. J. Mol. Sci. 2017, 18, 1607. [CrossRef] [PubMed]

64. Sharma, N.; Ostas, D.; Rotar, H.; Brantner, P.; Thieringer, F.M. Design and Additive Manufacturing of a Biomimetic Customized Cranial Implant based on Voronoi Diagram. Front. Physiol. 2021, 12, 443. [CrossRef]

65. Shidid, D.; Leary, M.; Choong, P.; Brandt, M. Just-in-time design and additive manufacture of patient-specific medical implants. Phys. Procedia 2016, 83, 4-14. [CrossRef]

66. Alfaify, A.; Saleh, M.; Abdullah, F.M.; Al-Ahmari, A.M. Design for Additive Manufacturing: A Systematic Review. Sustainability 2020, 12, 7936. [CrossRef]

67. Haug, R.H.; Nuveen, E.; Bredbenner, T. An evaluation of the support provided by common internal orbital reconstruction materials. J. Oral Maxillofac. Surg. 1999, 57, 564-570. [CrossRef]

68. Birkenfeld, F.; Steiner, M.; Kern, M.; Witlfang, J.; Möller, B.; Lucius, R.; Becker, S.T. Maximum forces applied to the orbital floor after fractures. J. Craniofac. Surg. 2012, 23, 1491-1494. [CrossRef] 